\title{
Broiler Chicken Meat Inspection Data in Brazil: A First Glimpse into an Animal Welfare Approach
}

\section{-Author(s)}

\section{Souza APO' \\ Taconeli CA" \\ Plugge NFIII}

Molento CFM'

Animal Welfare Laboratory, Federal University of Paraná, Rua dos Funcionários 1540, 80035-050, Curitiba, Paraná, Brazil.

" Department of Statistics, Federal University of Paraná, Centro Politécnico, 81531-990, Curitiba, Paraná, Brazil.

III Ministry of Agriculture, Livestock and Food Supply, Rua Romário Martins 625, 84165010, Castro, Paraná, Brazil.

\section{-Mail Address}

Corresponding author e-mail address Carla Forte Maiolino Molento

Universidade Federal do Paraná - Rua dos Funcionários, 1540, Curitiba/PR -

80035050 - Brazil.

Phone: +55 $413350-5788$

Email: carlamolento@ufpr.br

\section{nKeywords}

Animal-based indicators, carcass downgrading, risk analysis, welfare assessment, welfare surveillance.

\section{ABSTRACT}

We aimed to study the potential use of carcass condemnation data of broiler chicken slaughterhouses in Brazil as indicators in an animal welfare monitoring program, and to identify points to be addressed to increase data reliability. Data from 2010 to 2015 in the states of Paraná (PR), Santa Catarina (SC) and Rio Grande do Sul (RS) were used. Fractures and bruising were recorded together, representing the most prevalent welfare problem, followed by skin lesion or inflammation. In $P R$, progressive increases on injury, arthritis, ineffective bleeding, and air sacculitis condemnation may reveal important welfare aspects. High correlation between AWI within PR was more commonly observed than in RS and SC, perhaps as a result of earlier implementation of local meat inspection standardization. Principal component analysis showed changes on condemnation data pattern in PR after standardization, pointing injury and Escherichia coli problems as the main causes for condemnation related to animal welfare. There is considerable potential to improve animal health and welfare surveillance using meat inspection structure that is already in place for food safety purposes, provided that the competent authority harmonizes the procedure of meat inspection among the States, sets specific animal welfare outcomes to be monitored, and integrates condemnation, transport and flock data. It seems crucial to update data collection to establish a routine that allows risk analysis regarding both food safety and animal welfare. In this regard, cooperative work between Federal Inspection and companies seems an interesting approach to promote transparency of the production processes, which would benefit society and animals.

\section{INTRODUCTION}

Brazil is the second largest broiler chicken producer in the world. In 2015, about 5.2 billion broiler chickens were slaughtered in establishments under the Federal Inspection Service (SIF) of the Ministry of Agriculture, Livestock and Food Supply (MAPA), and there is a projection of a $46.4 \%$ increase in chicken meat production by 2023 . Simultaneously, there is an increasing demand for information on ethical aspects of animal production. Based on this, governmental actions are increasing worldwide. In the European Union (EU), Directive 2007/43/ CE (European Commission, 2007), on the protection of chickens kept for meat production, sets out compliance inputs for poultry farms, such as maximum stocking density, minimum lighting intensity, and air quality parameters. Additionally, outputs such as mortality and meat inspection data are considered with the purpose of establishing maximum stocking density values. Dermatitis, parasitic infections and systemic illness are also measured by the official veterinarian at the slaughterhouse to identify signs of poor welfare. 
Outcomes assessed at the slaughterhouse have the potential to improve animal welfare (Grandin, 2017). The use of carcass condemnation data as an official monitoring program of animal welfare (AW) is expected to promote practical consequences to animals, since feedback from slaughterhouse may gradually improve practices on farm (European Commission, 2017). However, based on the EU example, there are challenges to effectively implement such control, mainly regarding the variability of procedures among Member States (Butterworth et al., 2016). Thus, EU Members States organized a network for exchanging technical information to improve implementation of the Directive 2007/43/CE. Additionally, meat inspection data have been considered useful to investigate animal welfare (Correia-Gomes et al., 2017, 2016; HuneauSalaün et al., 2015; Knage-Rasmussen et al., 2015). Thus, creation and use of a meat inspection database seems to constitute a potential tool to improve public policies related to the welfare of farm animals. This seems also a practical approach, since there is a structure already in place with the primary purpose of controlling food safety, which may benefit AW actions.

In Brazil, the SIF is responsible for sanitary inspection at slaughterhouses under federal control and it is linked to the Department of Inspection of Products of Animal Origin (DIPOA) of the MAPA. Inspection is performed by a permanent team composed by official veterinarians and auxiliary staff. Activities performed by the SIF are regulated by the Decree 30,691, known as RIISPOA, which establishes the procedures of sanitary inspection of animal origin products (Brasil, 2017). Additionally, there is a specific regulation for the inspection of broiler chicken meat (MAPA, 1998). All carcass condemnation data obtained by SIF is recorded at the information management system (SIGSIF) and reports are publicly available.

According to Vannier et al. (2014), a set of harmonized welfare outcome indicators may be used by competent authorities in the framework of inspection and by private sectors to improve transparency in the market of animal products. Food production chain provides valuable data collection that can be used to improve disease control, animal health, public health and animal welfare. However, carcass condemnation data are not used for animal welfare purposes in Brazil. Our hypotheses were that broiler meat inspection data in Brazil comprises important AW indicators, and that adjustments are required to improve data collection. Thus, we aimed to study the potential use of carcass condemnation data of broiler chicken slaughterhouses in Brazil as indicators in an AW monitoring program and to identify points to be addressed to increase data reliability.

\section{MATERIAL AND METHODS}

Publicly available official slaughter and carcass condemnation data from January 2010 to December 2015 were obtained from the SIGSIF platform, MAPA website (www.agricultura.gov.br). Reports were generated in portable document format (PDF) and we transformed them into Exce ${ }^{\circledR}$ files to be analyzed. We then selected the three main producer States, Paraná (PR), Santa Catarina (SC) and Rio Grande do Sul (RS), all located in Southern Brazil. We analyzed general data regarding total and partial carcass condemnation in these three States. Additionally, we identified animal welfare target indicators (AWI) to be further assessed: abscess (ABS), airsacculitis/respiratory disease (AIR), arthritis (ART), ascites (ASC), bruises, contact dermatitis, dead on arrival (DOA), emaciation (EMA), dehydration, fracture, hepatitis (HEP), inadequate bleeding (INB), pericarditis (PER) and septicaemia (SEP)(EFSA, 2013, 2012; European Commission, 2007). Temperature $\left({ }^{\circ} \mathrm{C}\right)$ and humidity (\%) were collected from the National Institute of Meteorology (http://www.inmet.gov.br) for the same period to study correlations.

Meat inspection data was transformed in broiler chicken carcass condemnation per 100,000 birds. Descriptive statistics was used to verify the frequency of condemnations. Spearman rank correlation test was used to analyze the correlation between carcass condemnation data and climate variables, correlation of each condemnation cause between and within States. Correlations where $\mathrm{R}>0.6$ were considered high, and $0.6<R<0.3$ were considered moderate. Nonparametric change point analysis (James \& Matteson, 2013) was used to detect possible change points observed in carcass condemnation data from PR. Biplots based on Principal Component Analysis (PCA) were used to explore variance and covariance structure of data. PCA was based on the correlation matrix, using standardized data, to eliminate scale effects. The biplot was used to assess condemnation data and time simultaneously in a two-dimensional representation (Rencher, 2003). This technique was applied to data from PR to further understand the effect of the standardization of the data collection within the State, to allow comparison of the data in two periods, before and after the standardization procedure. Robustness of biplot was verified by identifying outlier values (López-de-Lacalle, 2016) and repeating data analysis by replacing outlier with values derived from the 
Souza APO, Taconeli CA, Plugge NF, Molento CFM
Broiler Chicken Meat Inspection Data in Brazil: A First Glimpse into an Animal Welfare Approach statistical average of previous and subsequent months. Analysis were performed using R Statistical Computing Environment version 3.3.1 (R Core Team, 2016).

\section{RESULTS}

The total number of broiler chickens slaughtered in Brazil under SIF, from January 2010 to December 2015, is observed in Figure 1. In Southern Brazil, almost 19 billion broiler chickens were slaughtered between 2010 and 2015, representing $62.2 \%$ of national broiler chicken production. Considering the 27 States in Brazil, there are 18 that produce broiler chicken meat, of which, Paraná accounts for one third of total national production.

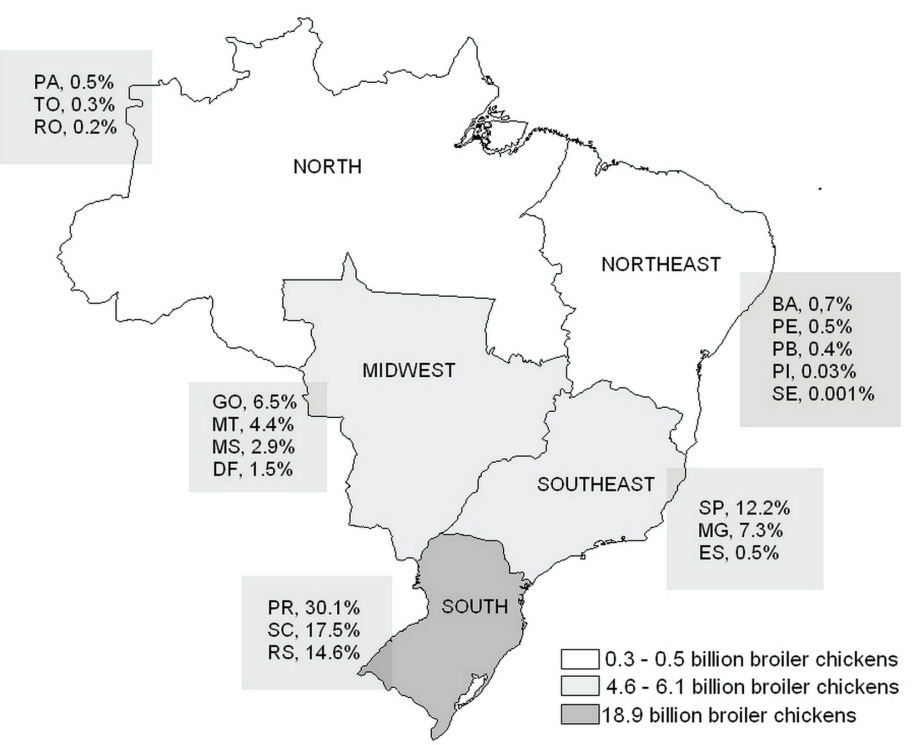

Figure 1 - Broiler chicken slaughter in Brazil, by state and region, from 2010 to 2015. Percentages refer to the proportion of the total of 30.4 billion broiler chickens slaughtered under Federal Inspection Service; PR, Paraná; SC, Santa Catarina; RS, Rio Grande do Sul; SP, São Paulo; MG, Minas Gerais; GO, Goiás; MT, Mato Grosso; MS, Mato Grosso do Sul; DF, Federal District; BA, Bahia; PA, Pará; PE, Pernambuco; ES, Espírito Santo; PB, Paraíba; TO, Tocantis; RO, Rondônia; PI, Piaui; SE, Sergipe.

General slaughter and carcass condemnation data for the States of Paraná (PR), Santa Catarina (SC) and Rio Grande do Sul (RS) are presented in Figure 2. In PR broiler chicken slaughter increased by $27.9 \%$ from 2010 to 2015, with increased carcass condemnation rates; the moment for the changepoint was statistically estimated to be March 2013. In SC and RS, broiler chicken slaughter was stable from 2010 to 2015, and a tendency toward increasing carcass condemnation reports through these years was not observed. Higher condemnation in 2015 in SC occurred due to an unusual peak of condemnation for dermatosis in February $(19,120 / 100,000$ birds slaughtered); this was not representative of the situation in SC. Excluding data from February/2015, condemnation rate in 2015 was slightly high in SC, reaching $5.6 \%$.

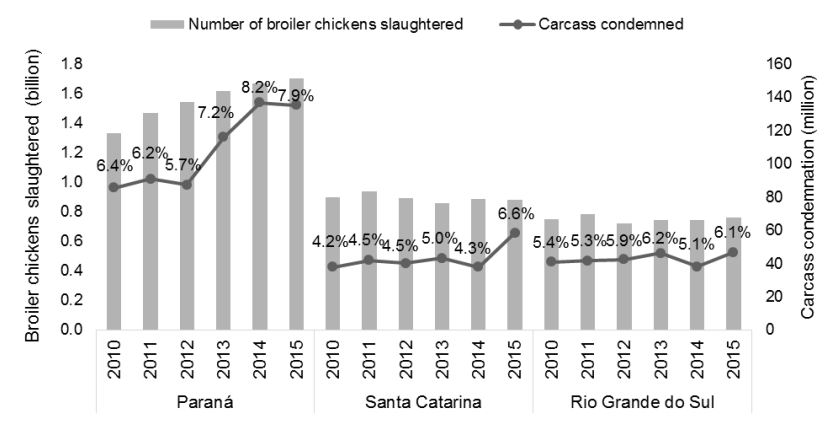

Figure 2 - Number of broiler chickens slaughtered, and number of carcasses condemned in the States of Southern Brazil, from 2010 to 2015. Columns refer to broiler chickens slaughtered, lines and percentages refer to carcass condemnation.

Animal welfare indicators and the main causes for carcass condemnation in PR, SC and RS are presented in Figure 3. Causes for condemnations that were below $80 / 100,000$ carcasses were presented as 'others', such as coligranuloma, over scalding, delayed evisceration, myositis, tumor, salpingitis and hemorrhagic syndrome. Paraná reported additional data for aspergillosis, hypertrophy and omphalitis; SC for colibacillosis and omphalitis; and RS for nephritis, myocarditis and enteritis. There was no record for the prevalence of contact dermatitis, DOA and dehydration.

Considering AWI, bruises and fractures were both registered as injury, with no discrimination between them. Injury was the main cause of condemnation in PR, SC and RS, representing, in 2015, 22.1\% of items condemned in PR, $19.4 \%$ in SC and $23.7 \%$ in RS. Dermatosis was the second most common cause in PR (14.8\%) and in RS (9.1\%). Increasing occurrence of a type of myopathy, named as dorsal cranial myopathy (MYO), was observed in the three States (Figure 3). From 2010 to 2015, MYO increased from $0.01 \%$ to $4.4 \%$ of total of carcasses downgraded in PR, being the sixth cause of condemnation in this State in 2015. In SC, MYO was the second cause of condemnation in 2015 , moving from $0.1 \%$ to $10.1 \%$ of total of carcasses downgraded; and it was the third cause of condemnation in RS, moving from $0.7 \%$ to $8.1 \%$.

In PR, high correlations between condemnation causes were more commonly observed than in RS and SC (Figure 4). Principal component analysis in PR showed changes in the condemnation data pattern after a standardization procedure was introduced in 2012 (Figure 5). For example, one group of indicators was strongly related with the component 1 , representing $39.4 \%$ of total data variability. The group was composed of the indicators INJ, ABS, AIR, CEL, COL and DER. Notification of indicators was strengthened in 2014 and 2015 in PR, observed by the distribution of dates in Figure 5. Outliers did not cause significant changes on the original data. 

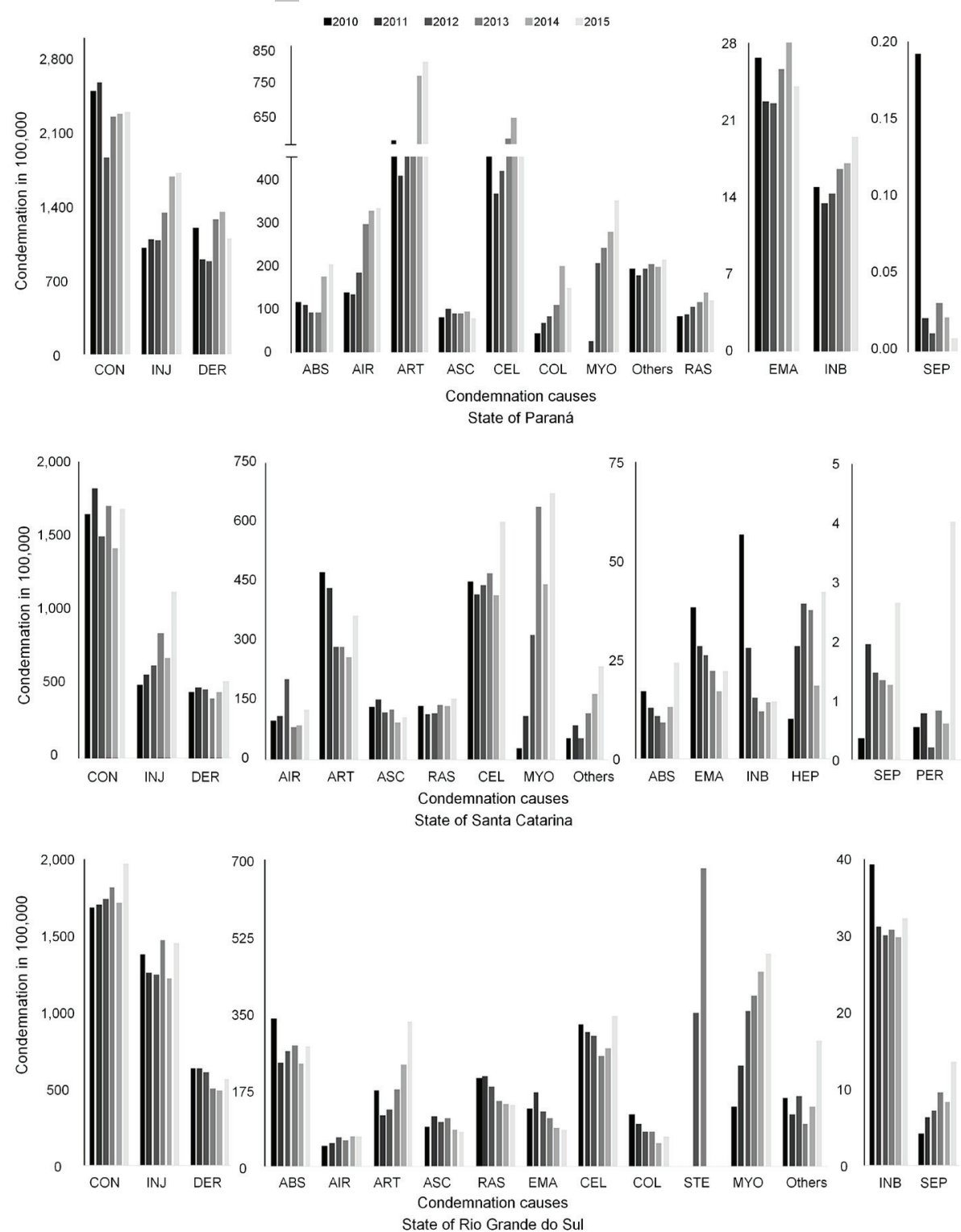

Figure 3 - Broiler chicken carcass condemnation per 100,000 birds in the States of Paraná, Santa Catarina and Rio Grande do Sul, Southern Brazil, from 2010 to 2015. CON, contamination; DER, dermatosis; INJ, injury; ABS, abscess; AIR, airsacculitis; ART, arthritis; ASC, ascites; CEL, cellulitis; COL, colibacillosis; STE, steatosis; MYO, dorsal cranial myopathy; RAS, abnorma aspect; EMA, emaciation; INB, inadequate bleeding; SEP, septicaemia; HEP, hepatitis; PER, pericarditis; others include all reasons for condemnations below 80/100,000 carcasses, except target animal welfare indicators of interest in this study.

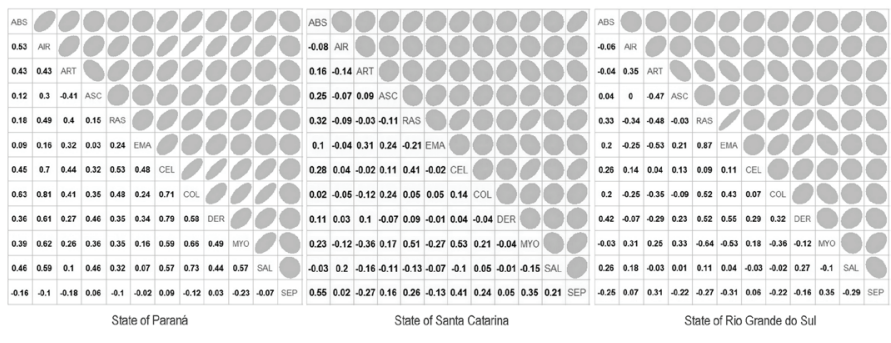

Figure 4 - Correlation of broiler chicken carcass condemnation indicators in the States of Paraná, Santa Catarina and Rio Grande do Sul, Southern Brazil, from 2010 to 2015 (broiler chicken carcass condemnation per 100,000 birds). ABS, abscess; AIR, airsacculitis; ART, arthritis; ASC, ascites; RAS, abnormal aspect; EMA, emaciation; CEL, cellulitis; COL, colibacillosis; DER, dermatosis; MYO, dorsal cranial myopathy; SAL, salpingitis; SEP, septicaemia; HEP, hepatitis; PER, pericarditis; ellipse shape is directly proportional to correlation strength, higher correlations appear close to an ellipse format; the orientation of the ellipse indicate positive (upwards to the right) or negative (upwards to the left) correlations.
We observed disparate values among the three States. As an example, condemnation data for abscess in RS and PR were, respectively, 21.0 and 8.8 times greater than the reported value in SC; and there was almost double the rate of condemnation for dermatosis in PR as compared to SC and RS. There was poor correlation in respect to condemnation rates among the three States. High correlation was observed for arthritis between PR and RS $(p<0.001 ; R=0.86)$, injury between PR and SC $(p<0.001 ; R=0.62)$, and for ascites between PR and SC $(p<0.001 ; R=0.66)$, PR and RS $(p<0.001 ; R=0.81)$ and between SC and RS $(p<0.001 ; R=0.83)$. Ascites was the only AWI that presented high correlation with a climate variable 
Souza APO, Taconeli CA, Plugge NF, Molento CFM
Broiler Chicken Meat Inspection Data in Brazil: A First Glimpse into an Animal Welfare Approach
(Temperature; SC, $p<0.001, R=-0.71 ; R S, p<0.001$, $R=-0.76 ; P R, p<0.001, R=-0.61)$. Other correlations between condemnation data and climate variables were moderate and low.
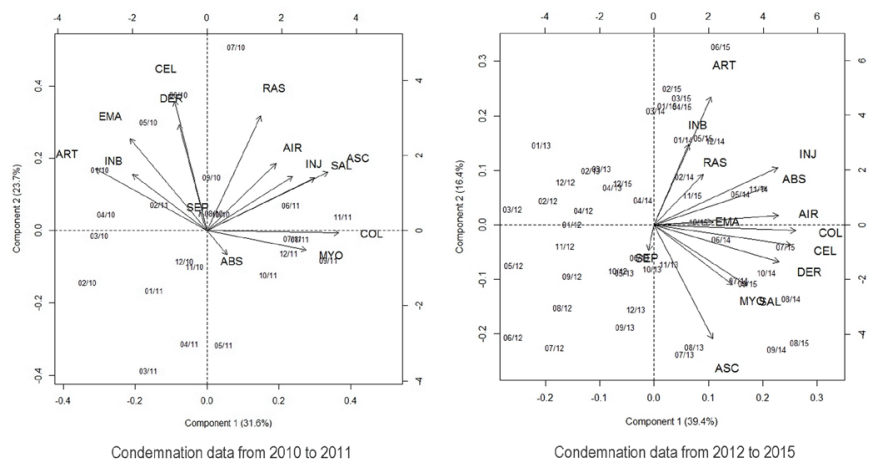

Figure $\mathbf{5}$ - Principal Component Analysis of broiler chicken carcass condemnation indicators in the state of Paraná, Southern Brazil, from 2010 to 2011, and from 2012 to 2015. DER, dermatosis; ABS, abscess; AIR, airsacculitis; ART, arthritis; ASC, ascites; CEL, cellulitis; COL, colibacillosis; MYO, dorsal cranial myopathy; RAS, abnormal aspect; EMA, emaciation; SAL, salpingitis; SEP, septicaemia; numbers inside the biplot represent month/year of the data derived from the database.

\section{DISCUSSION}

\section{Broiler chicken condemnation data in Brazil}

High prevalence of injury, skin problems and arthritis observed in Southern Brazil had already been observed in carcass condemnation data from 2006 to 2011(Oliveira et al., 2016); thus, these items have been important animal welfare issues in Brazil for a decade. Discrimination between bruises and fractures is described in scientific literature (Grandin, 2010) and is an important point to be improved with regard to meat inspection data in Brazil. Bruising and fractures used to be controlled separately as part of the MAPA Circular 294/2006, which established that companies had to implement self-monitoring programs, including animal welfare, and determined SIF as responsible for verifying those programs. Circular 294/2006 was repealed and current regulation about self-monitoring, Normative 01/2017, does not include the requirement for assessing injuries. In addition, data provided by self-monitoring programs were not recorded in the national database, and remain under used or even unused. Moreover, recognition of the relevance of injuries as a food safety problem may be variable amongst official veterinarians. Consequently, low values may be reported due to the acceptance of injured meat by less demanding markets or to be used as raw material in processed products. In this case, the inclusion of an AW concept to carcass condemnation data is encouraged to provide a standard procedure within all Brazilian States.
According to MAPA, dermatosis is a generic term used to record any skin or meat lesion without inflammation; and inflammatory processes, such as cellulitis and dermatitis, must be recorded as specific indicators (MAPA, 1998). There was no record of condemnation for contact dermatitis. In the case of footpad dermatitis, the absence of records occurred because broiler chicken feet with contact dermatitis are exported as lower grade product authorized by DIPOA to China and Hong Kong. In other cases, feet that were not marketed were discarded before inspection by the competent authority. Thus, since feet were not condemned, there was no official record about the incidence of footpad dermatitis. Since dermatosis includes a wide range of occurrences, it may contribute to high variability between SIF records, and is a potential item to be improved on data collection. In addition, considering that contact dermatitis is relevant to broiler chicken welfare (EFSA, 2012; European Commission, 2017), the implementation of an official monitoring program covering this issue seems crucial in Brazil.

Dorsal cranial myopathy (MYO) has been observed in Brazil since 2006, and it was reported as a lesion of the anterior latissimus dorsi (ALD) muscle (Zimmermann et al., 2012). Zimmermann et al. (2012) suggested that MYO is related to fast growing breeds, whose body is unbalanced and may cause intermittent interruption of blood flow of ALD when wings move over the large pectoral muscle of birds. Information about causes of MYO and its impact on animal welfare is scarce. Other studies about similar myopathies in broiler chickens have discussed the influence of genetics (Petracci et al., 2015) and both genetics and environment (Bailey et al., 2015). Due to the possible correlation of MYO with items that impact broiler chicken welfare and its intrinsic welfare impact, it seems an interesting indicator to be recorded and further studied.

In PR, where both percent condemnation and number of carcasses slaughtered increased, progressive increase in condemnation rates for injury, inadequate bleeding, arthritis and airsacculitis may indicate important welfare aspects to be considered. For example, injury may increase if employees are not adequately trained to handle live birds and if structure to transport live birds or staff responsible for catching and shackling birds is undersized (Grandin, 2010). In the case of PR, the competent authority at each slaughterhouse may accept carcasses or parts of carcass with small bruises. Nevertheless, condemnation for injury increased. Thus, we consider it important to assess whether the whole production chain structure, including activities where live birds are handled, 
presented a proportional increase as that observed in the number of broiler chickens slaughtered.

The extent of blood loss is affected by stunning, type of neck cut, time between stunning and bleeding and time for bleeding (Bilgili, 1988). All causes mentioned are controlled by SIF, by the national Ordinance 210/1998 and the Normative Instruction 3/2000. In addition, modification of the processing line speed must be approved by SIF regarding food safety concerns and proper post-mortem inspection. However, higher line speed combined with expansion of Halal meat exportation in PR may have affected bleeding efficiency. In PR, exportation of broiler chicken products to Middle East countries increased $70.0 \%$ from 2010 to 2015. Faster line speed requires more staff to perform neck cut during religious slaughter, thus space on the slaughter line and/or number of employees for neck cutting may potentially be insufficient. An indicator of bleeding efficiency based on the ratio between line speed and number of employees for manual slaughter may be an interesting approach to be studied in Brazil.

Condemnation for ART and AIR suggest that changes promoted in the broiler chicken industry in $P R$ in the last six years, like migration from natural lit poultry houses to those working exclusively with artificial lighting (Souza et al., 2015), had negative impacts on animal welfare and should be scrutinized from this perspective. Even though genetics has been pointed as the main cause for skeletal disorders in fast growing breeds, the lack of bird activity aggravates the problem (Bradshaw et al., 2002; EFSA, 2010). In the case of PR, broiler activity may have been reduced by both increased stocking density and low lighting, contributing to higher levels of skeletal disorders. High stocking density is also correlated to reduced air quality, increased heat stress and increased transmission of infectious diseases. Thus, higher condemnation for airsacculitis may indicate worse managing practices on farm since factors associated to the etiology of air sac disease are poor air quality, mainly high levels of dust and ammonia, associated with Mycoplasma gallisepticum or Escherichia coli infection (EFSA, 2012; Gross, 1961). Additionally, thermal conditions have the potential to cause stress and, thus, to decrease the immune response in poultry (Lara \& Rostagno, 2013), predisposing birds to disease.

Dead on arrival is controlled by SIF for each batch slaughtered and data may be recorded at SIGSIF. In addition, DOA higher than $1 \%$ must be reported to the Animal Health Service of each State, according to the MAPA Normative Instruction 17/2006. However, these data were not available for consultation and were not presented on SIGSIF condemnation reports, which prevented us to further study this indicator. In Brazil, both staff and a database to register this information are already in place. Thus, it seems feasible to standardize the procedure of registering and analyzing DOA, as well as making it publicly available, representing a structural advancement for the meat chain and public policies.

Correlations of ascites and temperature, as well as the correlation of ascites data among the three States in Southern Brazil, suggest it is a well-established health indicator at SIF. Disparate results in other indicators may be caused by several factors. Specific characteristics of each company, such as orientation to broiler chicken farmers, infrastructure, management policies, export market and labor will directly affect carcass condemnation data. Thus, it is possible that weak correlations between condemnation categories in certain states could be a consequence of combining data from companies with heterogeneous management practices and health problems, which may be further explored in future studies. However, lack of standardization is one weakness of meat inspection as health and animal welfare surveillance system (Huneau-Salaün et al., 2015). Based on our data, difference on carcass evaluation among SIF seemed to be the core point to improve quality of meat inspection data.

The specific Brazilian regulation about broiler chicken slaughter, Ordinance no. 210/1998, includes a list of condemnation causes to be reported by the SIF of each plant (MAPA, 1998). It is not an exhaustive list; however, it covers most of the selected AWI. In general, States in Southern Brazil recorded items demanded by national ordinance; however, each local SIF personnel may provide additional information and each State may standardize which items will be informed in the SIGSIF. This has created variations across States. Since 2009, MAPA has demanded States to set guidelines for the management of inspection service, including the standardization of post-mortem procedures. As an example, in PR, a group of official veterinarians met in 2012 to discuss about criteria for carcass evaluation and destination, and outputs from this meeting oriented SIF personnel in each slaughterhouse within the State. We observed that the standardization of procedures in PR took about one year to be fully visible, clearly dividing general condemnation data into two levels, before and after 2013 (Figure 2) and changing condemnation data pattern (Figure 5). It may be the result of strengthened training performed with SIF staff, in addition to possible problems related to 
broiler chicken chain. In RS, the memorandum 048/ SICAO/014 and a manual were published in 2014 and 2015, respectively, to guide official veterinarians within the State. As result, since 2014 data from RS seem better organized regarding terms used to describe cause and type of condemnation; however, information about downgrading of parts and giblets, including condemnation for hepatitis and pericarditis, was suppressed. Similarly, in PR condemnation of liver for hepatitis and heart for pericarditis have been recorded as carcass partial condemnation for colibacillosis since 2012, with the loss of valuable information. Thus, the standardization procedure adopted in Southern Brazil may lead to unreported indicators, reducing power of condemnation data as a surveillance system for animal health and welfare.

Higher coherence of indicators presenting high correlation in PR, as compared to SC and RS (Figure 4) may be a result of the standardization of meat inspection procedure. In contrast to PR, lack of high correlation among condemnation data in SC (Figure 4) may point variance on carcass judgment. The development and maintenance of a robust system of meat inspection data collection at national level is challenging. Regional organization of SIF proposed in Brazil may be more dynamic and improve activities within each State as compared to a national guidance; however, it may result in increased variation among States, creating uncertainty about the efficiency of Competent Authority in delivering reliable data. It seems advisable that standardization be either centralized at federal level by MAPA or that the regional organization be indirectly guided by MAPA.

\section{Federal Inspection Service potential to improve animal welfare in Brazil}

Brazilian Federal Inspection Service has been working to push companies to higher sanitary status to prevent foodborne diseases. This has been achieved through the implementation of hazard analysis and critical control points program (HACCP). In Brazil, since 1998 animal product processors are demanded to implement HACCP, but in broiler chicken slaughterhouses implementation has been strengthened since 2006, with the publication of Circular 668/2006. The same principle of hazard analysis for food safety concerns may be applied to animal welfare issues (Algers et al., 2009; Smulders, 2009). This is a new research area, and meat inspection data may facilitate its development. Potential AWI may be chosen as critical control points to be monitored, including the proposal of setting critical limits for AWI. Self-monitoring programs by companies may be an interesting approach to increase AW data collection, in addition to condemnation data collected by the competent authority. As stated by Short and Toffel (Short \& Toffel, 2008), success of selfmonitoring depends on the continued involvement of regulators with coercive powers. Thus, SIF supervision on food safety and animal welfare issues to support activities on animal production seems essential.

Brazilian government was moving to pass responsibility of meat inspection to industry. Reducing SIF operation will also affect surveillance in AW at the slaughterhouse, because it is part of the official veterinary activities. Similarly, in 2016 the Department of Environment, Food and Rural Affairs tried to put the welfare code on chicken farming under the control of the poultry industry in the United Kingdom. This process was interrupted mainly due to public opinion and pressure from non-governmental organizations. Recent disclosure of Brazilian Federal Police investigation related to meat inspection revealed high public concern about meat quality. Thus, it is advisable that the MAPA take public opinion into consideration, since consumers represents a powerful stakeholder in the food chain. In the case of Brazil, society was not inquired about the changes on food inspection system proposed by MAPA, which may be detrimental to the relation between society, government and industry.

\section{CONCLUSION}

The inclusion of an AW view on meat inspection data is a new concept that seems applicable to Brazil, since the data present information with potential use as AW indicators. Our results indicate a need to harmonize SIF procedures among States, to set specific AW outcomes to be monitored and to integrate condemnation, transport and flock data. Points to be improved include differentiation of bruising from fracture when recording these lesions; refined assessment of skeletal disorders and contact dermatitis; and monitoring the ratio of line speed and number of employees for neck cutting. Results suggest a need to update data collection to keep pace with modern animal production, as well to establish a routine of data analysis as part of risk analysis for both food safety and animal welfare. Overall, there is considerable potential to improve animal health and welfare surveillance using the structure of meat inspection that is already in place for food safety purposes, provided that MAPA addresses issues related to the weakness of data collection process. In this regard, cooperative work between Federal Inspection and companies seems to be an interesting approach to 
Souza APO, Taconeli CA, Plugge NF, Molento CFM

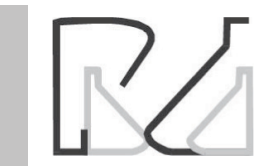

Broiler Chicken Meat Inspection Data in Brazil: A First Glimpse into an Animal Welfare Approach increase public information about animal welfare and to promote transparency of production process, which would benefit society and animals.

\section{ACKNOWLEDGEMENTS}

The authors wish to thank Liziè Pereira Buss who encouraged this study, the undergraduates Rita de Cássia G. Silva and Mariana Tiepo for data organization and two reviewers who offered valuable recommendations to this manuscript. We also acknowledge that Ana Paula de Oliveira Souza is the recipient of a CAPES (Ministry of Education, Brazil) doctorate scholarship.

\section{REFERENCES}

Algers B, Anil H, Blokhuis H, Fuchs K, Hultgren J, Lambooij B, et al. Project to develop animal welfare risk assessment guidelines on stunning and killing. EFSA Supporting Publication 2009;6:1-88.

Bailey RA, Watson KA, Bilgili SF, Avendano S. The genetic basis of pectoralis major myopathies in modern broiler chicken lines. Poultry Science 2015;94:2870-2879. Available from: https://doi:10.3382/ps/pev304.

Bilgili SF. Electrical stunning of broilers - basic concepts and carcass quality implications:a review. Journal of Applied Poultry Research 1988;135146.

Bradshaw RH, Kirkden RD, Broom DM. A review of the aetiology and pathology of leg weakness in broilers in relation to welfare. Avian and Poultry Biology Reviews 2002;13:45-103.

Brasil. Decreto 9013 de 29 de março de 2017. Regulamenta a Lei no 1.283 , de 18 de dezembro de 1950, e a Lei $n^{\circ} 7.889$, de 23 de novembro de 1989, que dispõem sobre a inspeção industrial e sanitária de produtos de origem animal. Brasília, DF; 2017.

Butterworth A, Jong IC, Keppler C, Knierim U, Stadig L, Lambton S. What is being measured, and by whom? Facilitation of communication on technical measures amongst competent authorities in the implementation of the European Union Broiler Directive (2007/43/EC). Animal 2016;10:302-308.

Correia-Gomes C, Eze JI, Borobia-Belsué J, Tucker AW, Sparrow D, Strachan $D$, et al. Voluntary monitoring systems for pig health and welfare in the UK:Comparative analysis of prevalence and temporal patterns of selected non-respiratory post mortem conditions. Preventive Veterinary Medicine 2017;146:1-9.

Correia-Gomes C, Smith RP, Eze Jl, Henry MK, Gunn GJ, Williamson S, et al. Pig abattoir inspection data: can it be used for surveillance purposes? PLoS One 2016;11:e0161990.

EFSA. Preparation of a data collection system of welfare indicators in EU broilers' slaughterhouses. EFSA Journal 2013;11:19-28.

EFSA. Scientific report updating the EFSA opinions on the welfare of broilers and broiler breeders. EFSA Supporting Publication 2012;9:116.

EFSA. Scientific Opinion on the influence of genetic parameters on the welfare and the resistance to stress of commercial broilers. EFSA Journal 2010;8:1-82.

European Commission. Laying down minimun rules for the protection of chickens kept for meat production [Directive 43/2007/EC]. Brussels; 2007.
European Commission. Study on the application of the broilers directive (DIR 2007/43/EC) and development of welfare indicators. Brussels: European Union; 2017. pp 261

Grandin T. On-farm conditions that compromise animal welfare that can be monitored at the slaughter plant. Meat Science 2017;132:52-58.

Grandin T. Welfare during transport of livestock and poultry.In: Grandin T, editor. Improving animal welfare: a practical approach. Oxfordshire: CABI; 2010. p.115-138.

GrossWB. The development of "air sac disease." Avian Diseases 1961;5:431-439.

Huneau-Salaün A, Stärk KDC, Mateus A, Lupo C, Lindberg A, Le BouquinLeneveu $\mathrm{S}$. Contribution of meat inspection to the surveillance of poultry health and welfare in the European Union. Epidemiology \& Infection 2015;143:2459-2472.

James NA, Matteson DS. ECP: an R package for nonparametric multiple change point analysis of multivariate data. Journal of Statistical Software 2014;62(7):1-25.

Knage-Rasmussen KM, RousingT, Sørensen JT, Houe H. Assessing animal welfare in sow herds using data on meat inspection, medication and mortality. Animal 2015;9:509-515.

Lara $L$, Rostagno $\mathrm{MH}$. Impact of heat stress on poultry production. Animals 2013;3:356-369.

López-de-Lacalle, J. Detection of Outliers in Time Series. In: López-deLacalle, J. Tsoutliers $T$ package. Vizcaya: University of the Basque Country; 2016.

MAPA - Ministério da Agricultura, Agropecuária e Abastecimento. Portaria 210 de 10 de novembro de 1998.Aprova o regulamento técnico da inspeção tecnológica e higiênico-sanitaria de carne de aves. Brasília, DF; 1998

Oliveira AA, Andrade MA, Armendaris PM, Bueno PHS. Principais causas de condenação ao abate de aves em matadouros frigoríficos registrados no serviço brasileiro de inspeção federal entre 2006 e 2011. Ciência Animal Brasileira 2016;17:79-89.

Petracci M, Mudalal S, Soglia F, Cavani C. Meat quality in fast-growing broiler chickens. Worlds Poultry Science Journal 2015;71:363-374.

R Core Team. A language and environment for statistical computing. Vienna: R Foundation for Statistical Computing; 2016.

Rencher AC. Methods of multivariate analysis. New York: John Wiley \& Sons; 2003.

Short JL, Toffel MW. Coerced confessions: self-policing in the shadow of the regulator. Journal of Law, Economics \& Organization 2008;24:45-71.

Smulders FJM. A praticable approach to assessing risks for animal welfare - methodological considerations. In: Smulders FJM, Algers B., editors. Welfare of production animals:assessment and management of risks. Wageningen: Wageningen Academic Publishers; 2009. p.239-274.

Souza APO, Sans ECO, Müller BR, Molento CFM. Broiler chicken welfare assessment in GLOBALGAP certified and non- certified farms in Brazil. Animal Welfare 2015;24:45-54.

Vannier P, Michel V, Keeling LJ. Science-based management of livestock welfare in intensive systems :looking to the future. Revue Scientifique et Technique 2014;33:153-160.

Zimmermann FC, Fallavena LCB, Salle CTP, Moraes HLS, Soncini RA, Barreta $\mathrm{MH}$, et al. Downgrading of heavy broiler chicken carcasses due to myodegeneration of the anterior latissimus dorsi: pathologic and epidemiologic studies. Avian Pathology 2012;56:418-421. 